OPEN ACCESS

Edited by:

Pradeep Nair,

Central University of Himachal

Pradesh, India

Reviewed by:

Vian Bakir,

Bangor University, United Kingdom

RamKumar Singh,

TERI School of Advanced Studies

(TERI SAS), India

*Correspondence:

Silvia Logar

logar.silviasara@gmail.com

Specialty section:

This article was submitted to Political Communication and Society,

a section of the journal

Frontiers in Communication

Received: 11 March 2021 Accepted: 22 October 2021

Published: 17 January 2022

Citation:

Logar S, Bednarova R, Rizzardo A and Miceli $L$ (2022) Uncertainty in Health Emergencies: Communicating Risks

During COVID-19 Response.

Front. Commun. 6:662179.

doi: $10.3389 /$ fcomm.2021.662179

\section{Uncertainty in Health Emergencies: Communicating Risks During COVID-19 Response}

\author{
Silvia Logar ${ }^{1 *}$, Rym Bednarova ${ }^{2}$, Alessandro Rizzardo $^{3}$ and Luca Miceli ${ }^{4}$ \\ ${ }^{1}$ School of Social Sciences, Humanities and Law, Teesside University, Middlesbrough, United Kingdom, ${ }^{2}$ Pain Division, Hospital \\ of Latisana, Latisana, Italy, ${ }^{3}$ Anaesthesia and Intensive Care, Papa Giovanni XXIII Health Authority, Monastier, Italy, ${ }^{4}$ Pain Division, \\ IRCCS CRO di Aviano, Padua, Italy
}

The world's fragmented response to the COVID-19 pandemic created fertile ground for mixed messages and inconsistency. The authors analyzed Google-trending insights from five countries (Italy, Spain, the United States, the United Kingdom, and France) across three-week time (1-23 March 2020) to document trends in population health anxiety in response to the initial global spreading of the outbreak. The results are expressed in the form of Uncertainty Index (UI), which reflects the total number of Google searches/COVID19 prevalence and standardized per million inhabitants. The United Kingdom experienced the highest level of health anxiety $(U I=11.5)$, followed by France $(U I=4.6)$ and Spain $(U I=$ 3.2). The United States suffered the highest rate of uncertainty in the early stage of the pandemic; the Italian population experienced a balanced level of anxiety. Institutionalizing risk communication during COVID-19 should represent an integral part of the country emergency response.

Keywords: risk, COVID-19, politics, communication, health emergencies

\section{TO THE EDITOR}

Institutionalizing risk communication represents an integral part of any emergency response.

Communicating risk during epidemics is critical in influencing public health strategies; hence, consistent and accurate information should be provided on time to the population (Miceli et al., 2017).

The COVID-19 pandemic situation has been particularly challenging as very little was known about the novel virus. Nevertheless, there seem to be large differences between individuals in terms of the perception of threat and the consequent fear (Fergus, 2015). Government sources of health information that are usually regarded as reliable because they provide accurate and unambiguous information were not necessarily perceived as authoritative and trustworthy when it comes to COVID-19. This crisis of confidence has been strictly related with diminished trust in political institutions during the pandemic, particularly when the adopted health policies of the governments openly contradict with recommendations provided by the World Health Organization or other relevant health agencies (Starcevic et al., 2020). For example, at the beginning of the pandemic, many governments refused the use of facemasks by the public due to a sense that their potential risks, such as self-contamination, could outweigh the potential benefits and that public use would lead to depletion of the supply needed for health-care workers. Systematic reviews of facemask use suggest relative risk (RR) reductions for infection ranging from 6 to $80 \%$, including for betacoronavirus infection (e.g., COVID-19, SARS, MERS). This inconsistency resulted in fragmented public health measures implemented by the policy makers (type of facemask, cost, equity, acceptability, and 

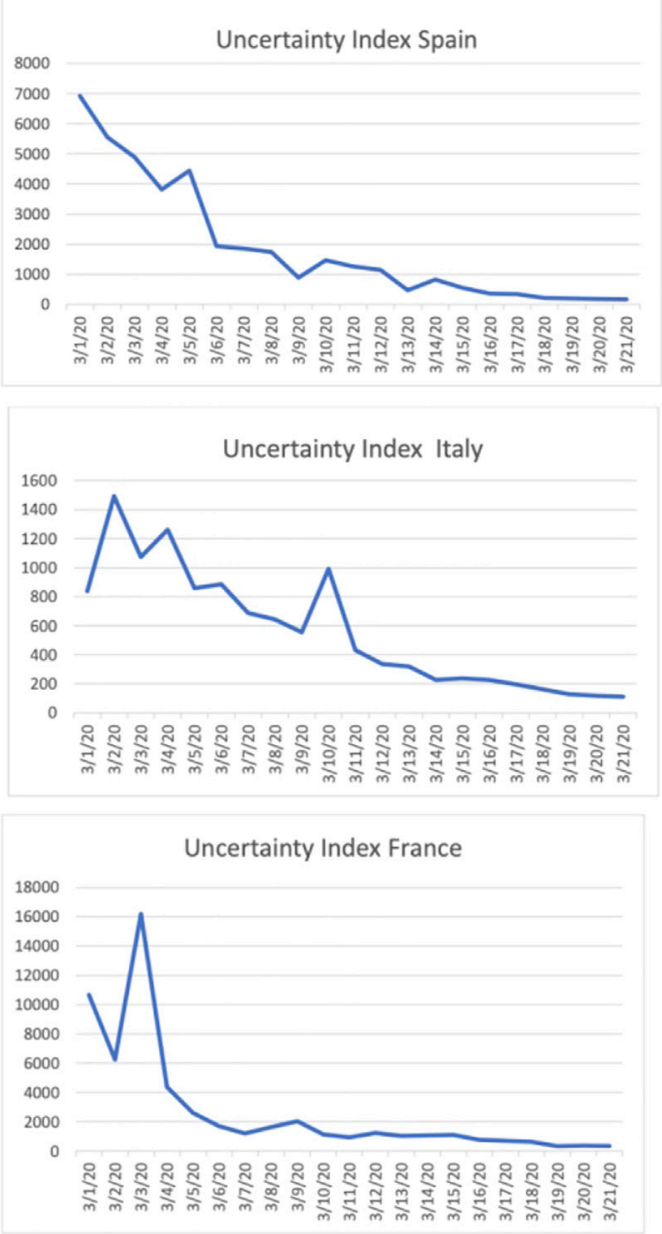

FIGURE 1 | Uncertainty Index Per Country.

feasibility). While most Asian governments required the public to wear masks from the beginning of the pandemic, governments in Western countries disagreed with wearing masks until they faced a vertical increase in the numbers of people who became infected (Schünemann et al., 2020).

Cyberchondria (CYB) has been described relatively recently as a behavior characterized by excessive online searching for medical information that is associated with increasing levels of health anxiety (Vismara et al., 2020). A recent systematic review revealed that CYB showed a self-reported association with health anxiety, hypochondriasis, and obsessive-compulsive disorder (OCD) as well as other forms of problematic usage of the internet (PUI). The psychological mechanisms associated with CYB include anxiety sensitivity, intolerance of uncertainty, and pain catastrophizing.

A list of factors that contribute to cyberchondria have been identified. These include, among others, 1) a heightened perception of threat and fear of a newly identified and poorly understood disease, 2) lack of authoritative and trustworthy sources of relevant health information, and 3) inability of excessive online health information seeking to provide the

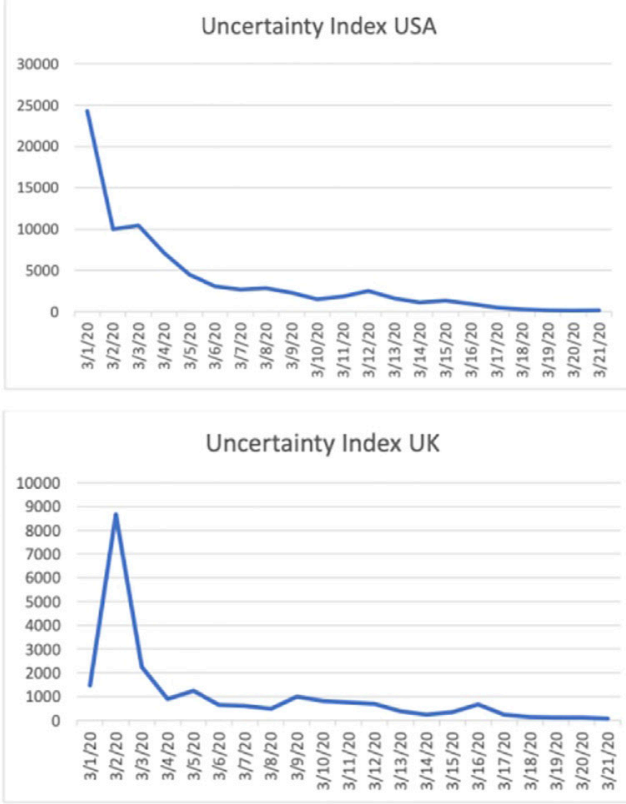

necessary information and deliver reassurance (Lauriola et al., 2019).

Assuming that compulsive search of a term on the internet may be taken as an indicator of uncertainty regarding a specific subject (Salkovskis et al., 2002), the authors analyzed Googletrending insights from five countries (Italy, Spain, the United States, the United Kingdom, and France) across threeweek time (1-23 March 2020) to document trends in population health anxiety in response to the initial global spreading of the outbreak. The selection of these countries has been driven by two elements: 1) they faced similar epidemiological situation in the beginning of the pandemic period (e.g., Italy has been the first country in Europe where the virus has been isolated; the United States reported the highest death rate during that period of time); 2) government and public authorities' declarations on COVID-19 national health policies for these countries have been freely accessible online. However, the authors believe that this methodology could be further escalated and adopted by other countries.

Google Trends, an open data tool that allows users to interact with Internet search volumes for user-specified terms, has been 


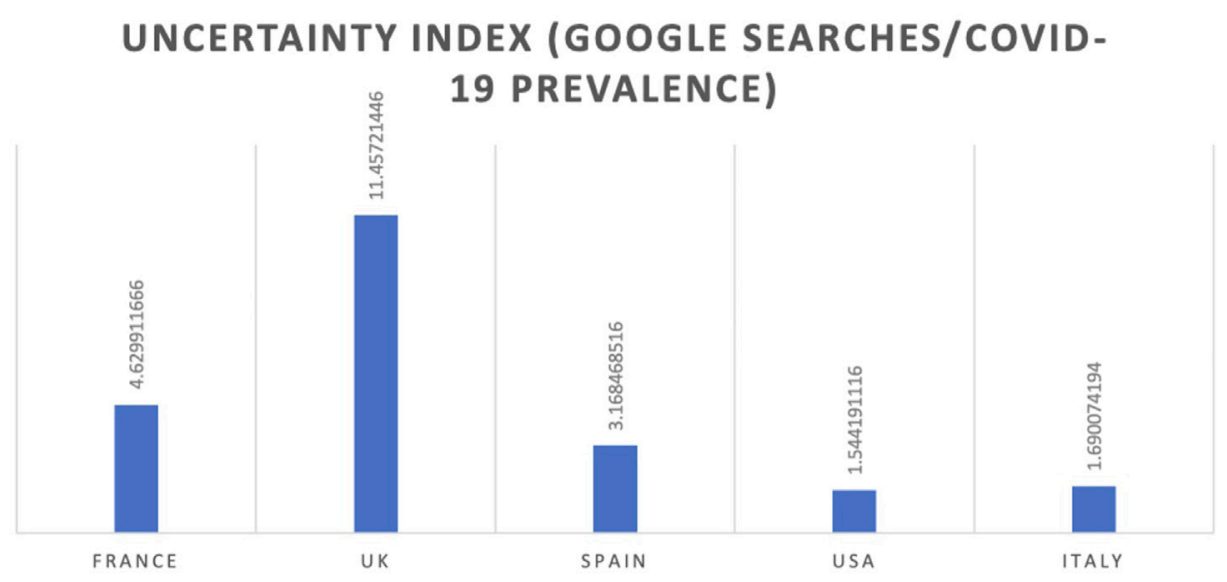

FIGURE 2 | Undertainty Index Standardized.

leveraged to determine the relative search volume for the term "coronavirus" performed on Google, normalized by the highest query share of word over the time-series (Hilger et al., 2019). Data have been then linked with the country COVID-19 confirmed cases/day ${ }^{1}$. The results are expressed in the form of Uncertainty Index (UI)", an original indicator reflecting the total number of Google searches/COVID-19 prevalence and standardized per million inhabitants.

The United Kingdom experienced the highest level of health anxiety $(\mathrm{UI}=11.5)$, followed by France $(\mathrm{UI}=4.6)$ and Spain $(\mathrm{UI}=$ 3.2) (Figures 1, 2). A large utilization of internet search activities characterized these countries, particularly in the earliest phase of the pandemic, regardless of COVID-19 incidence. Notably, time trend analysis indicates a decisive flattening of the uncertainty curves influenced by government declarations on COVID-19. On March 17, 2020, the Prime Minister Boris Johnson publicly urged the UK residents to comply with social distancing measures in response to the COVID-19 pandemic ${ }^{2}$. The declaration had an immediate effect on the Google searches, causing a drastic UI fall (from 658, March 16, 2020-130, March 18, 2020; Figure 1).

Spain, which was in the observed period the second COVID19 most affected country after Italy, passed a Royal Decree declaring the situation of emergency on March 14, 2020 $(\mathrm{UI}=819)$.

Following the announcement, the Uncertainty Index dropped to 551 , and since then, its values have stayed consistently below this level ${ }^{3}$.

${ }^{1}$ Google Trends, Available at: https://trends.google.com/trends/trendingsearches/ daily?geo=SG

${ }^{2}$ Guidance: what the coronavirus bill will do, Department of Health and Social Care (UK) Available at: https://www.gov.uk/government/publications/coronavirus-billwhat-it-will-do/what-the-coronavirus-bill-will-do

${ }^{3}$ Spanish Government, Real Decreto 463/2020, de 14 de marzo, por el que se declara el estado de alarma para la gestion de la situacion de crisis sanitaria ocasionada por el COVID-19 https://boe.es/boe/dias/2020/03/11/pdfs/BOE-A-2020-3434. pdf\#BOEn
On March 16, 2020, France imposed lockdown to control COVID-19 transmission. The same evidence applies to the country, experiencing a $50 \%$ reduction on its UI influenced by the Prime Minister declaration ${ }^{4}$. Nevertheless, the French government pandemic communication strategy has been largely criticized as confusing and inconsistent.

The United States suffered overall the highest rate of uncertainty in the early stage of the pandemic, reaching unprecedented peaks of single user accesses (24.000, March 1, 2020, Figure 1) ${ }^{5}$.

Instead of governmental entities, news media companies played a central role to respond to public inquiries by creating specified question and answer sites on their websites, such as the Wall Street Journal's (n.d.) "Coronavirus: You Ask, We Answer" site and CNN's "You asked, We are answering" (Yan, Andrew, Mahtani, and Kaur, n.d.) sites (Kim and Kreps, 2020a).

However, the curve fell sharply around March 6, 2020, when President Trump (Schünemann et al., 2020) signed into law the COVID-19 Preparedness and Response Supplemental Appropriations Act (UI = 1.5, Figure 1).

Italy described the lowest differential interval in the uncertainty values across the time trend analysis (Figure 1). The Italian government and media have alternated between alarmism and premature signals of a return to normality. Concern about the economic difficulties created by the virus has initially pushed the government to take excessively light measures. Despite the resulting instability in government communications, which has disorientated the Italian public to some extent, the population appeared to experience a balanced level of anxiety that is consistently decreasing over time, possibly influencing the daily government updates on the emergency situation (Torri et al., 2020).

While there is no "one size fits all" communications strategy to deliver information during a prolonged crisis, in this article, we draw

\footnotetext{
4"We are at war": France imposes lockdown to combat COVID-19. Available at: https://www.channelnewsasia.com/news/world/covid-19-coronavirus-francelockdown-macron-12544854
}

${ }^{5}$ Worldometer, Available at: https://www.worldometers.info/coronavirus/ 
on key findings from five countries to highlight some fundamental characteristics of effective governmental crisis communication.

When public health professionals and medical advisors to the top leaders of many countries warned about the severity and global spread of COVID-19 and asked for urgent preparation at the national level in the early stage of the global pandemic, particularly in January and February 2020, top leaders of many countries often downplayed what the experts suggested, and the public health threats did not garner much governmental attention (Kim and Kreps, 2020b). This has led to the highest level of uncertainty across the population, which is reflected with the UI curves, flattening as a result of institutional leadership against the pandemic (implementation/adoption of national measures to fight COVID-19).

There are unequivocal lessons learned from the current COVID-19 pandemic: 1) in the context of responding to emergencies with public health implications, inconsistent information and conflicting data may have negative impacts on population anxiety; 2) as individuals are required to make decisions based on having incomplete information, emergency

\section{REFERENCES}

Fergus, T. A. (2015). Anxiety Sensitivity and Intolerance of Uncertainty as Potential Risk Factors for Cyberchondria: A Replication and Extension Examining Dimensions of Each Construct. J. Affective Disord. 184, 305-309. doi:10.1016/j.jad.2015.06.017

Hilger, C., Otto, I., Hill, C., Huber, T., and Kendel, F. (2019). "Dr. Google" Informationssuche und Krankheitsangst bei Männern mit lokal begrenztem Prostatakarzinom. Urologe 58, 1050-1056. doi:10.1007/ s00120-018-0769-1

Kim, D. K. D., and Kreps, G. L. (2020). An Analysis of Government Communication in the United States during the COVID-19 Pandemic: Recommendations for Effective Government Health Risk Communication. World Med. Health Pol. 12, 398-412. doi:10.1002/ wmh 3.363

Kim, D. K. D., and Kreps, G. L. (2020). An Analysis of Government Communication in the United States during the COVID-19 Pandemic: Recommendations for Effective Government Health Risk Communication. World Med. Health Pol. 12, 398-412. doi:10.1002/wmh3.363

Lauriola, M., Tomai, M., Palma, R., La Spina, G., Foglia, A., Panetta, C., et al. (2019). Intolerance of Uncertainty and Anxiety-Related Dispositions Predict Pain during Upper Endoscopy. Front. Psychol. 10, 1112. doi:10.3389/ fpsyg.2019.01112

Miceli, L., Bednarova, R., Di Cesare, M., Santori, E., Spizzichino, M., Di Minco, L., et al. (2017). Outpatient Therapeutic Chronic Opioid Consumption in Italy: a One-Year Survey. Minerva Anestesiol 83 (1), 33-40. doi:10.23736/S03759393.16.11099-5

Salkovskis, P. M., Rimes, K. A., Warwick, H. M., and Clark, D. M. (2002). The Health Anxiety Inventory: Development and Validation of Scales for the Measurement of Health Anxiety and Hypochondriasis. Psychol. Med. 32, 843-853. doi:10.1017/s0033291702005822 risk communication activities can influence the perception of credibility of health authorities among affected populations, leading to confusion and unresponsive behavior; and 3) the effective integration of mechanisms for information sharing and communication coordination into national leadership structures for response to emergency events with public health implications is critical.

\section{DATA AVAILABILITY STATEMENT}

The original contributions presented in the study are included in the article/Supplementary Material, and further inquiries can be directed to the corresponding author.

\section{AUTHOR CONTRIBUTIONS}

All authors listed have made a substantial, direct, and intellectual contribution to the work and approved it for publication.

Schünemann, H. J., Akl, E. A., Chou, R., Chu, D. K., Loeb, M., Lotfi, T., et al. (2020). Use of Facemasks during the COVID-19 Pandemic. Lancet Respir. Med. 8 (10), 954-955. doi:10.1016/s2213-2600(20)30352-0

Starcevic, V., Schimmenti, A., Billieux, J., and Berle, D. (2020). Cyberchondria in the Time of the COVID -19 Pandemic. Hum. Behav Emerg Tech 3, 53-62. doi: $10.1002 /$ hbe 2.233

Torri, E., Sbrogiò, L. G., Di Rosa, E., Cinquetti, S., Francia, F., and Ferro, A. (2020). Italian Public Health Response to the COVID-19 Pandemic: Case Report from the Field, Insights and Challenges for the Department of Prevention. Ijerph 17 (10), 3666. doi:10.3390/ijerph17103666

Vismara, M., Caricasole, V., Starcevic, V., Cinosi, E., Dell'Osso, B., Martinotti, G., et al. (2020). Is Cyberchondria a New Transdiagnostic Digital Compulsive Syndrome? A Systematic Review of the Evidence. Compr. Psychiatry 99, 152167. doi:10.1016/j.comppsych.2020.152167

Conflict of Interest: The authors declare that the research was conducted in the absence of any commercial or financial relationships that could be construed as a potential conflict of interest.

Publisher's Note: All claims expressed in this article are solely those of the authors and do not necessarily represent those of their affiliated organizations, or those of the publisher, the editors and the reviewers. Any product that may be evaluated in this article, or claim that may be made by its manufacturer, is not guaranteed or endorsed by the publisher.

Copyright (c) 2022 Logar, Bednarova, Rizzardo and Miceli. This is an open-access article distributed under the terms of the Creative Commons Attribution License (CC $B Y)$. The use, distribution or reproduction in other forums is permitted, provided the original author(s) and the copyright owner(s) are credited and that the original publication in this journal is cited, in accordance with accepted academic practice. No use, distribution or reproduction is permitted which does not comply with these terms. 